\title{
Factors affecting the value of environmental predictions to the energy sector
}

\author{
Matt Davison ${ }^{1 *}$, Ozgur Gurtuna ${ }^{2}$, Claude Masse ${ }^{3}$ and Brian Mills ${ }^{4}$
}

\begin{abstract}
Background: Energy extraction, production, and transmission systems are highly sensitive to states of the natural environment such as temperature, wind speed, and even ice cover. Forecasts of such state variables are termed environmental predictions. How much value can such environmental predictions provide to the operator of a given energy system? This paper presents three illustrative Canadian case studies, selected to provide a good cross section across sectors, forecast types, and decision time scales, to provide insights into this important question.

Results: Using these case studies this paper examines what distinguishes economically valuable forecasts from economically less valuable forecasts. It is found that the risk aversion of the decision makers, the degree to which the decision has multiple inputs, and the certainty of the forecasts, together with the sensitivity of the system to the environmental variable in question, all play important roles.

Conclusions: To the extent that risk aversion results from government regulations and organizational guidelines, the conclusions suggest changes in public policy and industry practices that could help unlock value from currently underused forecasts.
\end{abstract}

Keywords: Weather information, Energy, Electricity, Value, Decision, Economics

\section{Background}

Energy is a fundamental input to the global economy and modern society. Despite technological advances, many aspects of the energy web-demand, production, transmission and distribution-remain sensitive and vulnerable to the fluctuating states and elements of the natural environment, as thoroughly reviewed in (Larsen, 2006). For example, temperature and humidity strongly influence electricity and natural gas consumption (Teisberg et al., 2005) while the rate of inflow of water to hydroelectric generating facilities affects the production of electricity (Hamlet et al. 2002). Tropical storms (Considine et al., 2002) and the trajectory of pack ice and icebergs in northern waters can both have a huge impact on natural gas and oil production.

Science and its institutions have developed a degree of skill in predicting temperature, wind speed, hurricane

\footnotetext{
* Correspondence: mdavison@uwo.ca

'Departments of Applied Mathematics and Statistical \& Actuarial Sciences and the Richard Ivey School of Business, The University of Western Ontario, London, ON, Canada

Full list of author information is available at the end of the article
}

tracks, and other environmental variables and their relationships with aspects of the energy system. While most people think of this as the domain of public meteorological and hydrometeorological agencies, the specialized private weather forecasting sector is occupying a greater share of this niche. Environmental predictions (EPs) provided by these enterprises become valuable to the extent that they reduce uncertainty in ways meaningful to decisions or actions taken by stakeholders in the energy system. The value of meteorological forecasts to the entire British economy is quantified by (Teske \& Robinson, 1994), a broader goal than that presented here. Efforts to quantify the value of EP to the energy sector are surprisingly absent in Canada, an energy-rich nation exposed to variable weather patterns.

The focus of this paper is on demonstrating the economic value of environmental prediction information to selected agents or enterprises involved in the production, transmission and distribution of energy. The aim is not to make an exhaustive estimate of the value of every possible EP to every participant in the Canadian energy sector but rather, by means of case studies, to identify factors allowing greater or lesser value to be extracted 
from EP. Thus, while the goals of this paper are narrower than (Teske \& Robinson, 1994), they are broader than the results reported by (National Renewable Energy Laboratory, 1995).

While the main objective of this work is to quantify the economic value of EP, broader notions of value, extending beyond the realm of cost reductions and profit maximization, should also include societal benefits such as reductions in adverse health effects from air pollution reductions. While not explicitly treated here, these broader metrics are valid and necessary elements of determining the societal value of better environmental predictions.

An overview of the environmental prediction valuation methodology is described. Several case studies highlighting specific weather and climate-sensitive aspects of the Canadian energy sector are then used to illustrate some of the non-environmental factors governing how the economic value of a prediction can significantly vary. The case studies are selected so much as to be representative of the Canadian energy environment but to illustrate the impact of various external criteria on forecast value. We agree with (Considine et al., 2002) that nonrisk averse or "expected value" decision makers are able to extract more value from (necessarily) imperfect weather forecasts than are safety oriented, worst case scenario minimizing decision makers. This study makes the added point that, even in the absence of significant risk to human life and welfare, the nature of regulatory constraints on energy system operators can influence whether they behave as expected value or worst case decision makers, and hence on their ability to extract value from EP. The paper concludes with implications for policy and future research. A complete account of this research is reported in (Turquoise Technology Solutions 2007).

\section{Methodology for valuing an environmental prediction}

Environmental predictions may allow entities in the energy sector to make better decisions. For example, knowing it will be hot tomorrow allows energy producers to plan for the resulting high demand. However, the forecast only has value if it reduces uncertainty: the forecast of a hot July day will be much less valuable than the forecast of an unexpected May heat wave. The "net benefit" value of the forecast can be quantified by determining the added financial value of these better informed decisions (Mason, 1966). In addition, entities must be able to integrate weather forecasts into their decision structures in order to benefit from a particular forecast (Stewart et al., 2004). Of course, for a forecast to be useful it must save more money than it costs to produce, with the caveat that there may be multiple uses for the same forecast.
A variety of approaches have been developed to value EP-like information as reviewed in (Turquoise Technology Solutions 2007). Early efforts to quantify the value of weather information are synthesized by (Macauley, 2005) which also sheds light on the cost/benefit decision of purchasing additional pieces of information. The latter decision problem is also described by several governmental bodies in (Danish Ministry of Transport, 2006; WMO Secretariat, 2007; NAV Canada, 2002). Early papers applying a classical decision science approach include (Baquet et al., 1976), who quantified the value of frost forecasts to orchard operators deciding whether or not to run heaters. A more general theoretical framework for this valuation problem was provided by (Hilton, 1981) while (Kite-Powell 2005) applied the theory to an ocean environmental data application.

The expected value is a cornerstone in many of these valuation frameworks. For example, suppose a power company must decide how to bid tomorrow's production from their various generation assets into tomorrow's market. Because this process is repeated every day and the possibility of bid leading to a catastrophic loss is very low, it makes sense to measure the effectiveness of a bidding strategy by its average performance, or expected value. In such a situation a slight edge in predicting temperature, hence demand, and hence electricity price, might have a small daily value but a large annual value.

However, the expected value is not always an appropriate metric. Hurricane forecasts to drilling rig operators in the Gulf of Mexico are valued by (Considine et al., 2002) who suggest that, unless a forecast brings near certainty, it is worth little. Oil rigs will be evacuated even at a slight chance of catastrophic weather conditions because the costs of a missed evacuation dwarf that of an unnecessary evacuation. An incremental improvement in the accuracy of the forecast is unlikely to change this decision.

\section{Results}

The current paper aims to draw qualitative conclusions about the characteristics of situations leading to valuable environmental forecasts. Its goal is not to quantify the value of all forms of EP to all sectors of the energy system. It proceeds by analyzing three representative cases. For more information about how these cases were selected and constructed, please see the Methods section.

\section{Electricity demand and temperature}

The framework for this case study summarizes the U.S. focused studies of (Teisberg et al., 2005) and (Hobbs et al., 1999) and use similar stylized facts about the general behaviour of energy systems. Although these works are not focused on Canada, the similar power systems 
and climate conditions of the two countries allow useful comparisons.

Because economically meaningful quantities of electricity cannot be stored, generation must match consumption in a dynamic manner. Consumption varies tremendously due to weather (i.e., air conditioning during heat waves and heating during extreme cold) and more regular patterns of use (e.g., lower demand during the night and on weekends or holidays). Electricity is most economically generated in large plants which produce it at a constant rate. Generating electricity at a moment's notice is much more expensive. For this reason, accurate demand forecasts, which in turn require accurate temperature forecasts are very valuable. This case study further develops the short term supply and demand aspects of this issue and outlines how the economic value of forecasts can be approximated.

Power demand is low at night and high during the day and tends to be lower on weekends and public holidays. Because of heating and cooling requirements, exterior temperature is a key power use driver. Figure 1 shows a plot of Ontario power demand against the temperature at Toronto's Pearson airport at two different hours of the day. The figure shows that when days are cold, power demand rises when temperature falls, while on hot days power demand rises with temperature. Since Ontario does not have a spatially uniform temperature, this relationship could be improved by use of temperature forecasts at various locations, but the figure is nonetheless instructive. It is also important to note that most of the other power use drivers, such as number of daylight hours and timing of weekends and public holidays are predictable and so do not require sophisticated forecasts

Matching this fluctuating demand requires an understanding of the economic and engineering features of the commonly used generation sources. A typical electrical system includes several generating technologies with different marginal costs of production. These plants are dispatched using solutions of the "unit commitment

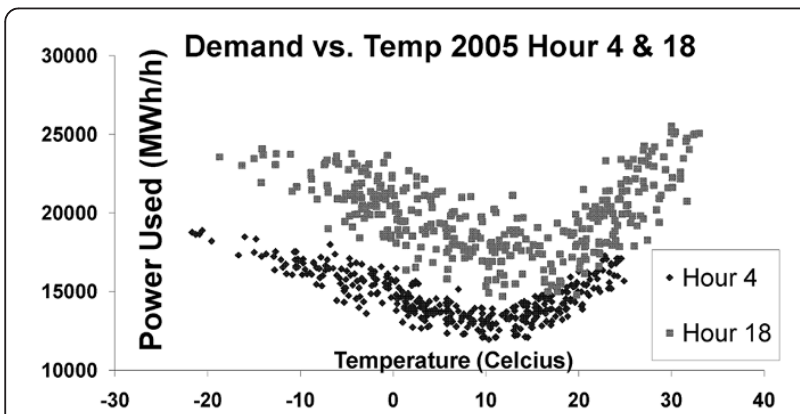

Figure 1 For hour 4 (4 AM-5 AM; darker diamonds) and hour 18(6 PM-7 PM; lighter squares) on every day in 2005, Aggregate Ontario load data is plotted against Toronto airport temperature data. Power Demand: Ontario IESO as archived by Dydex Inc (2007). problem" (Baldick 1995) that, for a given level of production, use the cheapest sources of power first. Power demand varies over the day, with predictable and unpredictable components, so unit commitment must be performed repeatedly to find the best variable generation mix over the course of the day. The dynamic nature of this process creates a complication since the output of some generation types cannot be adjusted quickly, if at all. The need to take these flexibility characteristics into account can result in plans which no longer use the absolute low-cost producer. For example, nuclear power must typically always be dispatched.

Highly responsive plants are therefore required to enable the variation of these plans. Two main methods can be used for this purpose: spinning reserve and Automatic Generation Control (AGC). A unit is part of the spinning reserve if, though ready to immediately do so, it is not generating any power. Plants running in AGC surrender operational control to the system operator, which operates them to balance system load. The technical and environmental issues around spinning reserve and AGC are reviewed in (NOAA/NESDIS 2002). AGC units are able to rapidly increase or decrease their output, as commanded, to respond to load changes. Thermal power plants operating in spinning reserves still consume significant amounts of fuel to "keep their boilers hot". Therefore improvements in temperature (and hence load) forecast accuracy can create both economic and environmental value by reducing the unnecessary use of spinning reserves. In a U.S. study, (Teisberg et al., 2005) found that accurate 24-hour temperature forecasts are worth US\$166 million per year in optimizing the generation mix.

It should be noted that the high value reported here results from the impact of small daily profits repeated day after day. This repeated decision framework means that small statistical improvements in decisions will, over time, contribute to significant value.

In contrast to the simple single variable/single repeated decision setting of this case study, there are situations when multi-factor forecast information may be valuable for tactical, operational and strategic decisions. These are discussed in the following section within the context of hydroelectric power.

\section{Hydrology case study}

Hydroelectric generation depends strongly on water inflows and water levels (Zhao \& Davison 2009a). Both flow rates and water levels vary over time, and this variability has a significant impact on the generation capacity of utilities. Indeed, (Hydro Québec, 2006) identifies hydrological inflow risk as its largest single financial risk factor, surpassing interest rate risk and foreign exchange risk. 
This case study quantifies the potential value of sophisticated hydrological EP to hydroelectricity companies across operational and tactical decision scales. The use of the term "potential" signifies the curious absence of EP in current industry practices.

\section{The value of hydrological EP to operational decisions}

On hourly time scales, accurate hydrological inflow predictions can be used to buffer electricity demand fluctuations much as temperature predictions were used in 3.1. Such forecasts can be obtained by accurately measuring upstream rainfall forecasts and using these as inputs to river flow models. This value can be quantified using the framework of (Hobbs et al., 1999).

Quick-response hydro allows the amount of water sent through the turbines to be changed on short notice. In jurisdictions with little hydro, the equivalent balancing services must be provided by more expensive spinning reserve, as discussed in section 3.1. The more accurate the short-term prediction of water inflows, the more prominent will be hydro's balancing role.

The value of accurate short term forecasts of water inflows can be captured by treating the power generated by a turbine as a negative source of demand, reducing the power required from the rest of the system. We ignore any diversification effect inherent in combining inflow and load uncertainty and consider only the savings attributable to EP by requiring less backup for uncertain hydro inflows. Since the more uncertainty the more valuable the forecast which reduces this uncertainty, including diversification would reduce this forecast value. This approach to valuing short term hydrological forecasts lies within the theoretical framework of (Hobbs et al. 1999) which allows the value of a decrease in mean absolute percentage error (MAPE) of a load forecast to be assessed. Specifically, a $1 \%$ reduction in MAPE is reported to decrease variable generation costs by $0.1 \%-0.3 \%$ when MAPE is in the range of 3-5\%, while (Ranaweera et al. 1997) suggest that MAPE is between $2 \%$ and $5 \%$.

In Alberta, (very seasonal) hydroelectric power generation accounts for about $1000 \mathrm{MW}$ of an 11,500 MW market. During peak flow (freshet) season, when power output is highest, the output variability is negligible. At the end of the fall, when natural water flows are lowest, variability is also negligible as flows are the result of planned reservoir withdrawals. The following analysis is based on dams operated by TransAlta corporation on the Bow River and South Saskatchewan river systems and uses information provided by a TransAlta hydrologist (Lin 2006). The two rivers have appreciable variability in water inflows for 3 months of the year. This variability is measured by a capacity factor, the ratio of average annual river energy production to the amount which would be produced if the generating stations were always working at full output). This capacity factor is $31 \%$ and $21 \%$ for the Bow and North Saskatchewan river systems respectively, so we assume a capacity factor of $25 \%$ in the following calculation. During this season, the hydrological inflows uncertainty at a given dam is about $10 \%$ over the 2 -day time window. As the TransAlta corporation alone has 13 dams on the Bow and North Saskatchewan River rivers systems we can suppose that the actual variability over the entire system is scaled down, by diversification and adopting an independence assumption, to $10 \% / \sqrt{ }(13)$, or about $3 \%$. If hydrological forecasts could reduce uncertainty in operational scale river inflow forecasting by an estimate of about $1 / 3$ they would therefore result in a further $1 \%$ improvement of hydro system MAPE.

This improvement saves about $0.2 \%$ of the variable generation cost during that same time period (Hobbs et al. 1999). Saving $0.2 \%$ of the $\$ 50 / \mathrm{MWh}$ marginal cost natural gas fuelling Alberta's variable generation is $\$ 0.10 / \mathrm{MWh}$. Over three months, a 1,000 MW facility working at $25 \%$ capacity factor generates 546,000 MWh of electricity, implying overall cost savings of $\$ 55,000$ per year for Alberta. While this conservative estimate is based on strict assumptions, even multiplying by ten would not generate material savings.

Hydrological EP can also play an interesting role in the timing decisions of hydro operators when it comes to generating power now or storing water for later. The operator of a hydroelectric facility with water storage ability can profit from fluctuations in the price for electrical power. If a power system contains a mix of hydroelectric and other variable output fossil fuel generators, during periods of low power prices water can be held back and the amount of hydro power generated can be decreased, being replaced by fossil fuel generated power. The amount of water saved can then be channelled through the turbine during high power price periods. Implementing this strategy requires overcoming challenges in predicting both power prices and water inflows.

In regulated markets with time-of-day pricing, the price is deterministic. Even in deregulated markets, (Davison et al. 2002) show that the price results from the balance between the load and the supply of power. Over short time horizons, the power supply is largely predictable, barring unlikely unplanned outages. The short term power demand is almost entirely determined by foreseeable time-of-day and day-of-week effects and the temperature, which can be predicted accurately over 1-3 days (see section 3.1 ).

In order to isolate the value of improved hydrological EP in this decision problem, (Zhao \& Davison 2009b) consider a simple model of a hydroelectric facility operating in a market with time-varying but deterministic power prices and hourly water inflows following a simple random model. They compute the optimal facility 
operating strategy and the resulting facility expected value using a dynamic programming approach. By modelling the problem with a 48-hour time horizon, (Zhao \& Davison 2009b) assume that, while the form of the stochastic model governing the future inflows is known, the actual inflows are unknown. Stochastic dynamic programming is used to calculate the optimal control and the associated value of the pump storage facility. Next, they assume that the future inflows, although generated from sampling within the same stochastic model, are known and use deterministic dynamic programming to obtain the optimal controls and associated values for each set of inflows. Finally, using Monte Carlo techniques they compute the average of these two values. The first optimal control assumes random inflows, the second assumes deterministic inflows simulated from the same distribution as the random inflows. They conclude that an accurate 48-hour flow forecast increases the value of the hydroelectric facility by about $2 \%$.

In order to determine the value of this prediction capability for the Alberta setting, we use the same base case scenario, but this time with storage as an additional model feature. If we take the $2 \%$ savings at face value, then the annual value of perfect 48-hour load forecasts to Alberta will be approximately $\$ 3$ million per year. Since for 9 months of the year water storage is not an option and the best strategy available is "use it or lose it", even perfect forecasts cannot yield value. Hence, on an annualized basis, $\$ 750,000$ is the appropriate prediction value.

\section{The value of hydrological EP to tactical decisions}

In large watersheds longer hydrological forecasts are possible. Reservoir levels can be used to manage seasonal fluctuations in demand as well as to profit from seasonal price fluctuations. This is done by selling hydro production to neighbouring markets when prices are high and, when prices are low, conserving water in the reservoirs for future use.

The ability of such "water trading" entities to generate profits from time varying electricity prices in neighbouring markets is limited by the ability to store water. Even the largest reservoirs cannot prudently be filled above an upper threshold nor drawn down below a lower threshold. If future water inflows are uncertain, these "safety limits" must be computed by taking into account certain risk factors. If, on the other hand, future water inflows can be well characterized, water supplies can be managed much more aggressively. This approach has significant potential economic value as described by (Hamlet et al. 2002).

Watersheds are typically used by many stakeholders. Rivers provide hydroelectric generation, recreational opportunities, and unique habitats for fish and other flora and fauna, and the tension between these demands constrains the use of the rivers. Moreover, regulators tend to be very risk averse and prefer erring on the more conservative side when it comes to managing water levels. Such conservative protocols, while ensuring adequate water levels at all times and for all purposes, also have the negative effect of leaving a lot of unused water in most years-water which could have been used to generate valuable hydroelectric power. If a better forecast of extreme levels is possible, and if this forecast is accepted by regulating bodies, it can actually provide significant economic value.

The information provided by TransAlta hydrologist (Lin 2006) together with data on variable Alberta electricity market prices, was used to obtain a rough estimate of the value of annual EP projections for the Alberta market. In addition to the system capacity factor described in section 3.2.1, an important parameter for a hydroelectric system is the storage capacity which denotes the ratio of the amount of water that can be stored in the reservoir to the average annual flow rate. This storage capacity is $24 \%$ for the Bow River system and $44 \%$ for the North Saskatchewan river. TransAlta's reservoirs are drawn down to their minimum capacity each spring to prepare them to accept as much of the spring runoff as possible.

In Alberta the power price fluctuates according to a deregulated market. According to the Alberta Electric System operator (2007), in 2005-2006 power could be sold for $\$ 116.31$ per MWh during low flow OctoberDecember times (\$142.14 during "on peak:" daytime weekday hours), while in high flow April-June average prices were much lower at $\$ 50.06, \$ 61.14$ for on peak power. This price variability makes the ability to save water for use in October-December very valuable: we suppose that such storage could allow power to be sold for $\$ 100 / \mathrm{MWh}$ rather than $\$ 50 / \mathrm{MWh}$.

The Columbia river study of (Hamlet et al. 2002) suggests that the difference between a dry-and a wet-year is substantial-this is also the case in the intermittent $\mathrm{Al}$ berta market. Assume that an EP application for annual Alberta flow rate allowed for an additional 10\% of the high capacity spring runoff water to be stored for release in the late summer or winter high price season. In this case, the value of EPs for the Alberta market is very significant: about \$3.6 million (accounting for the difference between the roughly $\$ 100 / \mathrm{MWh}$ available during the high demand, low flow months and the roughly $\$ 50$ / MWh available during the spring months). Despite this large potential value, our interviews did not reveal significant use of seasonal forecasts in Alberta, a point of discussion we leave for section 4 .

In summary, the value of temperature forecasts to the electricity industry relies to a great extent on the fact 
that expected value decision making is possible. An agent like a utility can use weather information to support its decisions and take actions that will reduce costs or hedge against financial risk. This is not always the case, as shown in the case study presented in the next section.

\section{Sea ice environmental predictions for offshore oil and gas production}

Not unlike the case of hurricanes affecting oil and gas production in the Gulf of Mexico (Considine et al. 2002), both drifting sea ice (pack ice) and icebergs can be a threat to offshore oil platforms in northern waters, such as those tapping the Jeanne D'Arc basin located below the Grand Banks, East of Newfoundland (Hibernia, Terra Nova, and White Rose). These three sites respectively produce about 314,000, 150,000 and 100,000 barrels per day of light crude oil (Offshore technology, 2006). All three locations are at risk not only from icebergs, which given the shallow $80 \mathrm{~m}$ depths can scour the ocean floor and damage underwater infrastructure, but also from floating sea ice at thicknesses of 1-2 m. It is interesting to note that different oil platform technology has been selected for these sites.

The Hibernia Oil Platform is a fixed "gravity based structure" (GBS) which is designed to be nearly invulnerable to the encroachment of sea ice or icebergs. This invulnerability comes at the heavy financial cost of $\$ 1$ billion for the additional reinforcement (Ralph, 2007). In contrast, the extraction at the Terra Nova and White Rose sites is accomplished by means of a floating production, storage, and offloading vessel (FPSO) that can be disengaged in response to a severe ice threat. In the latter case, the timing of the decision to disengage is critical. If the vessel is moved in response to every threat, production will be delayed at a high cost. On the other hand, if the vessel never leaves, it will be at risk to damage from ice. Coupled with this set of decision processes is a complicated threat management environment which allows sea ice and icebergs to be diverted from the structure using icebreakers and even water cannons. Environmental predictions of the trajectory of floating sea ice and icebergs are an integral part not only of the threat management system but also of the evacuation system.

To obtain insight into the challenges of incorporating forecasts into sea ice/iceberg management for offshore operations, simple expected value decision experiments for the FPSO case are discussed below. However, while the risk to life and limb from floating sea ice is low (Ralph, 2007; Kirby 2007) icebergs present significant catastrophic loss risk. The need to heavily weigh such catastrophic events in decisions will decrease the following estimates.
The decision may be framed by assuming that the platform is surrounded by three concentric circles, denoting various threat levels. Each successive breach by an iceberg or sea ice reduces the time remaining to the decision maker and forces an intermediate shutdown so that, if necessary, there is enough time to evacuate.

Assume that the FPSO services an oil well, modelled on White Rose, with a daily production of 100,000 barrels of light crude (sold on the international market), and a production lifetime of 10 years. An ice threat (sea ice or iceberg) arriving at the outer perimeter of a given concentric circle will take a given time to hit the oil platform.

The following analysis is constructed to model how a decision maker would incorporate ice forecast information in FPSO movement decisions. It does not represent detailed industry practice. In the absence of forecasts, the probability of ice breaching a given area is assumed proportional to that area. Additional information about the direction from which ice threats typically come will change this scaling relationship (if ice always comes from the north, the probability of ice breaching a circular region is proportional to its diameter).

For indicative purposes only, assume that the outer circle has a radius three times and the middle circle a radius twice that of the inner circle. The resulting probability of ice breaches must follow in the progression 9:4:1. For the purpose of this analysis, we assume that, during an assumed 30-day ice season, the outer circle is breached $9 \%$ of days. Countermeasures involving serious economic loss need only be initiated as the second circle is breached, so this corresponds to an assumption of approximately 1.33 times per year of second circle events and approximately once every 3 years of extremely serious, inner circle breach events.

A threat protocol to safeguard the oil platform workers and the natural environment is instituted so that when the outer circle is breached by ice, the steps of a shutdown and evacuation sequence are initiated. We consider a three-level threat model. When ice is outside the outer concentric circle, a threat level of zero exists. When ice breaches the outermost circle, the FPSO makes ready for sea, incurring a modest cost in fuel burned. If the ice leaves the outermost circle again, this step can be reversed. If, on the other hand, ice continues to breach the second circle, the FPSO must shut down oil production, at a much heavier cost. Even ignoring any petroleum engineering consequences, the result is to defer production of oil from the present to the end of the reservoir's life. This incurs a known cost of 100,000 $\mathrm{x}$ today's oil price, with a countervailing benefit of $100,000 \mathrm{x}$ the oil price 10 years from now, discounted to the present day at an appropriate interest rate (spread over the London Interbank Offered Rate, LIBOR). If we 
assume that today's oil price is US\$70 per barrel, discounted at $6 \%$, and that the value of oil grows simply with a $2 \%$ inflation rate, the cost of deferring a day's production is about $\$ 2.25$ million. Naturally, this result is very sensitive to the underlying oil price assumptions.

Further, assume that the ice leaves the middle circle after a single day (either to breach the inner circle or to retreat to the outer circle), and that if the ice retreats to the outer circle, production can be restarted immediately. If the ice breaches the innermost circle, the FPSO needs to disconnect from the wellhead and steam away. The cost of this is estimated to be an entire week of lost production-to cover the time required to steam to safety, return, and perform the delicate operation of re-connecting to the wellhead.

A mobile escort vessel armed with water cannon and having tug and icebreaking capabilities can provide safety countermeasures. Such vessels cost about $\$ 25,000 /$ day (Ralph, 2007) and are employed to redirect (with cannon or towing) icebergs out of the threat area and to break up floating sea ice.

We assume that employing such a vessel without using forecasts clears the threat at each stage with a fixed probability. Employing a vessel will be nearly worthwhile if its use for a single day reduces the probability of a middle circle breach lasting one day by even $1 \%$. However, the vessel cannot come on a day-by-day basis. It must be engaged monthly at a cost of $\$ 750,000$. Even though the Hibernia, White Rose, and Terra Nova oil platforms lie within a few hours steaming of one another so perhaps could share a single vessel, the cost of engaging it may not be worthwhile if the probability of an ice-related shutdown is small.

The expected value of environmental prediction information is assessed by carrying through two sets of calculations, one with and one without ice forecasts. The base case computes the expected annual cost of ice to an offshore platform similar to the White Rose without any use of countermeasures such as escort vessels nor any use of environmental prediction. This provides a baseline against which the other strategies can be judged. Four percent of the time the middle circle is breached. A middle circle breach requires a one day production shutdown at a cost of one day's deferred production, estimated to be $\$ 2.25$ million. As we assume 30 ice risk days in a year so the total cost of this middle circle breach is $30 \times 0.04 \times \$ 2.25=\$ 2.7$ million. Conditioned on the middle circle being breached, onequarter of the time the inner circle is breached next. An inner circle breach requires a shutdown for 7 days (after which it is assumed that the ice has left the outermost threat circle) at a cost of 7 days of lost production. Again, there are 30 ice days in a year so the cost of an inner circle breach is $\$ 4.725$ million. So the total expected annual cost of ice, with no countermeasures and no use of environmental prediction, is about $\$ 7.4$ million.

A more realistic variation of the base case assumes that an escort vessel is employed for the 30 days. The cost of the escort vessel is shared between 3 platforms at a daily cost of $\$ 25,000$ for a total cost of $\$ 0.25$ million per platform. We assume that $10 \%$ of the time, the escort vessel is able to stop a floating ice threat from moving from one threat level to the next higher level. When the escort vessel is present, the middle circle is breached only $4 \% *(0.9)^{2}=3.24 \%=$ of the time, and the inner circle is breached just $(0.9)^{3} \times 1 \%=0.729 \%$ of the time. So the expected loss due to ice decreases to $\$ 5.6$ million. As the escort vessel costs $\$ 250,000$, the total expected loss with escort vessel is $\$ 5.85$ million. This represents a savings of $\$ 1.55$ million relative to the original base case, suggesting that with the crude assumptions employed here, an escort vessel is well worth the money even in the absence of EP.

What is the effect of EP on the latter variation of the base case? In essence, good EP allows the threat regions to be shrunk, reducing the probability of having to engage in costly countermeasures. The better the EP, the more comfortable we can be with nearby ice and the more confident we can be about the escort vessel's ability to avert threats. Under reasonable assumptions quantifying these effects (Turquoise Technology Solutions 2007), the net effect is to save $\$ 3.98$ million, a substantial improvement from the $\$ 1.55$ million saved by the escort vessel alone or of the $\$ 740,000$ saved by passive EP alone. We can therefore attribute a significant savings of $\$ 3.98$ million - $\$ 1.55$ million $=\$ 2.4$ million to the incremental benefit of EP in this context.

Discussions with stakeholders (Dewhurst, 2007) emphasized that weather forecasts were used by stakeholders on an operational level, but mostly to minimize danger due to high winds and high seas rather than to forecast ice movement. Because of the time pressure under which such decisions are taken and their multifactor nature, it is difficult to isolate the value of a decision framework such as that described here.

The case studies presented here suggest that predictions of environmental variables ranging from temperature to water inflows and levels to the motion of floating ice in the ocean all have value to different participants in the Canadian energy industry. However, a recurring theme arising in our discussions with many stakeholders was that, despite this potential value, the full possibilities of environmental predictions were rarely being used. In the next section of this paper we address the reasons for this apparent failure and present some policy recommendations which could release more value from these forecasts. 


\section{Discussion}

Why isn't EP used where results suggest it would be very beneficial? For example, before 2007, the Alberta utility we interviewed was not using hydrological EP to manage their hydroelectric assets, although they were at that time considering the purchase of some hydrological decision support tools. One reason for this lies in the extreme complexity of making hydrological forecasts in the highly variable Rocky Mountain fed waterways. The priorities of other river stakeholders must be respected, and legal structures forbidding water levels below or above given thresholds must be obeyed. The addition of these constraints means that even if information allowing positive expected value decisions exists, the potential for the worst case arising from these decisions to breach legal limits eliminates the value to act on this information.

This dynamic was seen to be operating in the (Hamlet et al. 2002) analysis of hydrological prediction strategy on the Columbia river watershed. The U.S. Army Corps of Engineers restricts outflows on the Columbia River watershed using very conservative "observed worst year" or only slightly less conservative "observed third worst year" data. Worst case or "minimax" decision makers are often in the poorest position to make use of probabilistic $E P$, since the reduction of a remote, though possible, event to an even more remote, yet still possible event does not change worst case scenarios at all. Therefore, for conservative organisations such as the Corps of Engineers which are more concerned with mitigating ill effects than in optimizing frequent effects, minimax decision making is a natural tendency. This factor came up repeatedly in decisions involving physical as well as financial danger, negatively impacting the practical value of EP (for example in the case of sea ice forecasts).

Another reason for not using environmental forecasts which arose in discussions with both hydrological and ocean rig stakeholders was the multifaceted nature of decisions. When a decision depends on many variables, reducing uncertainty in just one of the variables may not be that valuable, even if reducing uncertainty in all of them might be. Such an example impacts the subject of the current study since the value of an improved forecast for just one of two uncertain inputs to a decision is often hard to realize. Even if the forecast is important, quantifying its value to the decision can be very difficult, especially after the fact.

These insights suggest some policy implications. Although extreme caution must be used when taking decisions involving human life and injury, it is possible that some laws could be rewritten in terms of exceedence frequency (e.g., the water level can fall below this limit a maximum of 5 minutes per day) or by replacing outright prohibition by fines. This would allow less than perfect forecasts to be used even by expected value decision makers, with the case-by-case potential to unlock a great deal of value. Of course, care must be taken to change regulations only when the impact on non-economic aspects of value is both acceptable and well understood.

For multi-faceted decisions, other financial tools such as forwards markets and hedging programs can, where appropriate, be used to limit exposure to market fluctuations, allowing the operators of businesses subject to environmental risk to extract more value from long range climate forecasts while controlling the risks related to economic and financial factors.

\section{Conclusions}

This study presented an analysis, in a Canadian context, of the value of various environmental predictions or forecasts to various participants in energy markets. The case studies presented show that value is dynamic and varies by decision time scale, location, and situation. The case studies described here were based on expert opinions, plausible assumptions or parameters obtained from the literature, however more research is required to substantiate the effect of improved hydrometeorological information on decisions.

The case studies demonstrated that expected value decision makers who can key on a single factor when making their decisions are much more likely to extract value from probabilistic forecasts than worst case avoiding decision makers. To support this conclusion, we saw that while temperature forecasts are routinely used by power generators in solving the unit commitment problem, use of hydrological forecasts was less common in the operation of Alberta hydro dams. While weather forecasts were used in oil rig operations, they were not yet being used to forecast the motion of floating pack ice and icebergs. To some extent this is a chicken and egg problem until forecasts get better, they will not be valuable to worst case focused decision makers, but they won't get sufficiently customized until they are used on an operational basis. As a result, framing regulations to enable expected value decisions might facilitate various agents to improve bespoke forecasts and hence extract more economic value from advanced scientific forecasts.

Finally, expanding on the traditional 'economic' definition of value to include social, cultural, and environmental factors might entirely change the final numbers; however, until such definitions become internalized in business or regulatory decision-making, considering them will yield little or no real impact.

\section{Methods}

The case studies reported here are selected from those analyzed for the broader study reported in (Turquoise Technology Solutions 2007), which were selected to represent decisions taken over operational (less than one 
week), tactical (one day to one year), and strategic (more than one year) time scales and were chosen to highlight various EP modalities and various important aspects of the Canadian energy system including energy production, transmission, distribution and consumption.

This paper presented three cases: the value of in the first case temperature and in the second case hydrological forecasts to the electricity generation sector followed by a case developing the value of sea ice and iceberg predictions to the offshore oil and gas production sector. The cases were constructed by incorporating results from U.S. and European studies and developing simple, yet plausible expected value decision experiments and analyses. To the extent possible, real agent experience and expert opinions were used to elucidate relevant aspects of the decision problem such as environmental and economic thresholds.

\section{Competing Interests}

The authors declare that they have no competing interests.

\section{Authors' Contributions}

This paper arose from a consulting project performed by OG and MD for Environment Canada. BM and CM, who work for Environment Canada, were on the steering panel for this project and were instrumental not only in selecting the case studies presented here from a broader menu but also in introducing $\mathrm{OG}$ and $\mathrm{MD}$ to valuable contacts and in providing feedback on the project. MD and OG developed the case studies, reviewing the published literature, performing the interviews and creating the models presented here. MD drafted this paper from a more comprehensive report co-authored by MD and OG; all authors gave detailed feedback on this paper is it progressed through the various publication stages. All authors read and approved the final manuscript

\section{Acknowledgements}

The authors would like to thank anonymous referees for their insightful comments which have improved this paper. MD thanks the Canadian Natural Science and Engineering Research Council and the Canada Research Chairs Program for financial support.

\section{Author details}

'Departments of Applied Mathematics and Statistical \& Actuarial Sciences and the Richard Ivey School of Business, The University of Western Ontario, London, ON, Canada. ${ }^{2}$ Turquoise Technology Solutions Inc, Montreal, Canada. ${ }^{3}$ Environment Canada, Montreal, Canada. ${ }^{4}$ Adaptation and Impacts Research, Environment Canada, Waterloo, Canada.

Received: 14 May 2012 Accepted: 14 August 2012 Published: 14 August 2012

\section{References}

Alberta Electric Systems Operator: http://www.aeso.org, accessed May 2007 Baldick R (1995) The generalized unit commitment problem. IEEE Trans Power Syst 10:465-475

Baquet AE, Halter AN, Conklin FS (1976) The Value of Frost Forecasting: A Bayesian Appraisal. Am J Agric Econ 58:511-520

Considine T, Jablonowski C, Posner B, Bishop CH (2002) The Value of Hurricane Forecasts to Oil and Gas Producers in the Gulf of Mexico. J Appl Meteorol 43:1270-1281

Danish Ministry of Transport (2006) Meteorology: A Revenue Generating Science: A Mapping of Meteorological Services With An Economic Assessment Of Selected Cases. The Ministry of Transport and Energy, Denmark

Davison M, Anderson CL, Marcus B, Anderson K (2002) Development of a Hybrid Model for Electrical Power Spot Prices. IEEE Trans Power Syst 17:257-264

Dewhurst M (2007) Oceans Inc meteorologist, personal communication
Hamlet AF, Huppert D, Lettenmaier DP (2002) Economic Value of Long-Lead Streamflow Forecasts for Columbia River Hydropower. J Water Resour Plann Manage 128:91-101, March/April

Hilton RW (1981) The Determinants of Information Value: Synthesizing Some General Results. Manage Sci 27:57-64

Hobbs BF, Jitprapaikulsarn S, Konda S, Chankong V, Loparo K, Maratukulam DJ (1999) Analysis of the Value for Unit Commitment of Improved Load Forecasts. IEEE Trans Power Syst 14:1342-1348

Hydro Québec (2006) Annual Report

Kirby N (2007) Personal communication with Mr. Kirby, seaman

Kite-Powell H (2005) Estimating Economic Benefits from NOAA PORTS Installations. A Value of Information Approach, NOAA Technical Report NOS CO-OPS 044, pp 3-5

Larsen PH (2006) An Evaluation of the Sensitivity of the U.S. Economy Sectors to Weather. M.Sc. Thesis, Cornell University, http://hdl.handle.net/1813/2957

Lin LL (2006) (TransAlta Inc) personal communication October 2006

Macauley MK (2005) Discussion Paper 05-26, Resources for the Future. In: The Value of Information: Measuring the Contribution of Space-Derived Earth Science Data to National Resource Management., , http://www.rff.org

Mason BJ (1966) The Role of Meteorology in the National Economy. Weather 21:383-393

National Renewable Energy Laboratory (1995) Estimating the Economic Value of Wind Forecasting to Utilities

NAV Canada (2002) Assessment of Aerodrome Forecast (TAF) Accuracy Improvement

NOAA/NESDIS (2002) Geostationary Operational Environmental Satellite System GOES-R Sounder and Imager Cost/Benefit Analysis

Offshore Technology (2006), http://www.offshore-technology.com/projects, accessed July 2006

Power load data: Ontario Independent Electricity System Operator, http://www.ieso. ca, accessed May 2007

Ralph F (2007) Personal communication with C-CORE. Engineer, July, 2007

Ranaweera DK, Karady GK, Farmer RG (1997) Economic Impact Analysis of Load Forecasting. IEEE Trans Power Syst 12:1388-1392

Stewart TR, Pielke R, Nath R (2004) Understanding User Decision Making and the Value of Improved Precipitation Forecasts: Lessons from a case study. Bull Am Meteorol Soc 85:223-235

Teisberg TJ, Weiner RF, Khotonozad A (2005) The Economic Value of Temperature Forecasts in Electricity Generation. Bull Am Meteorol Soc 86:1765-1780

Temperature data: Environment Canada: 2007. http://www.climate.weatheroffice. ec.gc.ca/ClimateData/canada_e.html, accessed May 2007

Teske S, Robinson P (1994) The Benefit of the UK Met Office to the National Economy. Conf Econ Benefits Meteorol Hydrol Serv 630:21-24, WMO/TD

Turquoise Technology Solutions (2007) Environmental Predictions and the Energy Sector: A Canadian Perspective. Report commissioned by Environment Canada, In

WMO Secretariat (2007) Sustainable Living-Reducing Risks and Increasing Opportunities: The Social and Economic Benefits of Meteorological and Hydrological Services: Issues and Actions

Zhao G, Davison M (2009a) When does variable power pricing alter the behavior of hydroelectric facility operators? Renew Energy 34:1064-1077

Zhao G, Davison M (2009b) Valuing Hydrological Forecasts for a Pump Storage Facility. J Hydrol 373:453-462

doi:10.1186/2193-2697-1-4

Cite this article as: Davison et al.: Factors affecting the value of environmental predictions to the energy sector. Environmental Systems Research 2012 1:4. 